\title{
AGRICULTURAL SUPPLY RESPONSE UNDER CONTRACT
}

\author{
BRENT HUETH AND ETHAN LIGON
}

\begin{abstract}
We consider four environments in which agricultural producers might operate, and for each of these we study the role of price and production risk in shaping farmers' supply-response decisions. In the first and second environments, farmers market their own produce and are risk neutral and risk averse, respectively. In the third environment farmers are risk averse, but we also allow for risk neutral intermediation. Interestingly, the model in this environment predicts that farmers should not face any production or price risk. In the final environment we continue to suppose the existence of risk neutral intermediation, but admit the possibility of private information for farmers. This last environment rationalizes exposure to production and price risk, and suggests that in such an environment a farmer's response to a change in expected price (ceteris paribus) will be less pronounced than in any of the other environments.
\end{abstract}

\section{INTRODUCTION}

Agricultural producers typically face considerable production and price risk in their operations. As a result $\Gamma$ the role of risk in shaping farm-level decisions has been the focus of much research (e.g. $\Gamma$ Moschini \& Hennessey 1998). But why do risk-averse producers face such risk? In a world of complete markets and perfect information $\Gamma \mathrm{a}$ profit-maximizing intermediary would provide full insurance to producers. Thus Tsome aspect of the production and marketing of agricultural commodities must limit the scope for this type of insurance. When considering reasons why growers of fresh produce might face price risk $\Gamma$ Hueth \& Ligon (1998) suggest the possibility of unobserved actions in the provision of quality. If quality can't be measured perfectly $\mathrm{T}$ and some downstream price contains information about a farmer's investment in quality then conditioning a grower's compensation on this price may help the intermediary to monitor farmer effort. A similar argument holds in the case of production risk: if unobserved actions

Date: November 30, 1998.

Prepared for presentation as an invited paper at the annual meetings of the Allied Social Science Associations, January 1999, New York. 
influence yield Tan optimal compensation scheme might expose farmers to considerable production risk in order to provide incentive for high output.

This suggests that the type of intermediation available to farmers can have important consequences for the risks that farmers face. Previous analyses of the role of risk in producer decisions make one of two polar assumptions regarding intermediation: either there is none

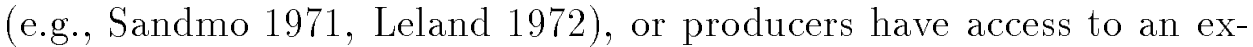
ogenously specified source of intermediation that may take the form of a futures market (e.g. THolthausen 1979) Г public or private insurance (e.g. TRamaswami 1993Г Babcock \& Hennessey 1996) Tor perhaps a particular government program (e.g. TChavas \& Holt 1996 Lin 1977). Although each of these analyses represent important contributions toward an understanding of how producers respond in different risk environments $\Gamma$ they are each silent on how the institutions themselves respond to risk. For exampleГhow might the risk faced by producers change when a new seed variety is developed that increases crop value and simultaneously results in less predictable yields? And how might supply response by producers be different in this new environmentTrelative to the status quo? These are the types of questions we seek to answer in this paper.

Toward this end Twe develop a model of intermediation in which the degree of insurance afforded farmers varies endogenously as a function of the environment (preferences $\Gamma$ technology $\Gamma$ endowments $\Gamma$ and information) in which farmers and intermediaries operate. For comparison with previous analyses Wwe first evaluate the role of risk in shaping the supply-response decisions of a single risk-neutral and then risk-averse farmer in an environment with no intermediation. Without intermediation $\Gamma$ the farmer's compensation is governed by the joint distribution of prices and outputs. A comparison of supply response in each of these environments is similar in spirit to the analysis of Sandmo (1971). We then continue to suppose that the farmer is risk averse $\mathrm{Cbut}$ also allow for risk neutral intermediation. Here we obtain results analogous to those of Holthausen (1979) and others who find some degree of separation between supply and marketing decisions. Interestingly $\Gamma$ the model in this environment predicts that the farmer should not face any production or price risk; the farmer's compensation is governed by a degenerate distribution. In the final environment Twe continue to suppose the existence of risk neutral intermediation $\Gamma$ but admit the possibility of private information for the farmer. In this environment Texposure to production and price risk emerges endogenously as an optimal response to an incentive problem. If the farmer cannot affect prices $\Gamma$ then his 
compensation will be independent of prices; furthermore This compensation will be governed not by the distribution of output $\Gamma$ but rather by the distribution of a likelihood ratio relating output to the private information of the farmer. In the final section we present the results of a numerical simulation comparing optimal payment mechanisms and supply response for each of the environments considered.

\section{THE MODEL}

A single farmer chooses an action $a \in A$ that influences the distributions of price $p \in P$ and output $q \in Q .{ }^{1}$ Although in some cases we might regard the stochastic processes governing $p$ and $q$ to be independent $\Gamma$ we initially suppose that $(p, q)$ are jointly distributed with cumulative distribution function $G(p, q \mid a)$ and density $g(p, q \mid a)$ Tassumed continuously differentiable and strictly positive on $(p, q) \in P \times Q$. Larger $a$ comes at cost $c(a)$ Tassumed increasing and strictly convex.

A risk-neutral farmer marketing his own produce chooses $a$ to maximize expected surplus $\Gamma$ given by $\int p q d G(p, q \mid a)-c(a)$. An interior solution to this maximization solves

$$
\int p q \frac{g_{a}(p, q \mid a)}{g(p, q \mid a)} d G(p, q \mid a)=c^{\prime}(a)
$$

where $g_{a}(p, q \mid a)$ represents the partial derivative of the density function $g(p, q \mid a)$ with respect to $a$. This will be referred to as the risk-neutral solution. The marginal cost of taking action $a$ appears on the right hand side of this expression $\Gamma$ and the marginal benefit to the grower appears on the left. From this expression $\Gamma$ we see that the marginal benefit is just the grower's expected revenue Twhere the distribution of $(p, q)$ has been adjusted by the likelihood ratio $g_{a}(p, q \mid a) / g(p, q \mid a)$.

In similar fashion $\Gamma$ a risk-averse farmer with differentiable utility function $U(\cdot)$ chooses a to maximize $\int U(p q-c(a)) d G(p, q \mid a)$ एyielding

$$
\int\left\{U(p q-c(a)) \frac{g_{a}(p, q \mid a)}{g(p, q \mid a)}-U^{\prime}(p q-c(a)) c^{\prime}(a)\right\} d G(p, q \mid a)=0
$$

for an interior solution. ${ }^{2}$ Equations (1) and (2) can be used to assess the effect of risk aversion on the farmer's supply decision. For exampleI does a risk-averse farmer produce more or less output than a riskneutral farmer? Sandmo (1971) demonstrated that Tin the presence of

\footnotetext{
${ }^{1}$ Price may depend on the farmer's actions either because his actions affect the quality of the commodity being marketed, or because the farmer faces an inelastic demand curve.

${ }^{2}$ Throughout the rest of this paper, we will suppose that non-zero, finite solutions to equations (1) and (2) exist, and are associated with unique maxima to the farmer's decision problem in each case.
} 
price risk alone the answer is less when the farmer's decisions do not affect the distribution of price. Pope \& Kramer (1979) prove a similar result in the case of production risk: in a competitive environment $\Gamma$ a risk-averse farmer will produce less than a risk-neutral producer $\Gamma$ provided that his inputs are risk-increasing.

We now continue to suppose that the farmer is risk averse that risk-neutral intermediation is possible. The intermediary is residual claimant for total revenues $p q$ Tand makes a payment $w(p, q)$ to the farmer that may depend on both realized price and output. ${ }^{3}$ If the farmer chooses $\Gamma$ he can produce on his own and achieve an expected utility $\underline{U} \cdot{ }^{4}$ Initially Twe suppose that the action $a$ taken by the farmer is observable to the intermediary. The intermediary solves

$$
\begin{array}{r}
\max _{a,\{w(p, q)\}} \int[p q-w(p, q)] d G(p, q \mid a) \\
\int U(w(p, q)-c(a)) d G(p, q \mid a) \geq \underline{U}
\end{array}
$$

For each $p$ and each $q$ Tthe choice of payment scheme $w(p, q)$ solves

$$
\lambda=\frac{1}{U^{\prime}(w(p, q)-c(a))}
$$

where $\lambda$ is the Lagrange multiplier for the farmer's participation constraint in (3). Although we allow for dependence of $w$ on both $p$ and $q \Gamma$ because $\lambda$ is constant (for given $\underline{U}$ ) $\Gamma$ it turns out that an optimal payment schedule provides the farmer with full insurance against any production and price risk. Furthermore Cit's not difficult to verify that for an interior solution and binding participation constraint $\Gamma$ the optimal action taken by the producer will be identical to that of the risk-neutral producer marketing his own output. The intermediary therefore maximizes expected net revenue and promises the producer a constant payment just sufficient to ensure participation.

In actual markets for agricultural commodities $\Gamma$ farmers are often exposed to considerable levels of both production and price risk. The level of insurance that's available against these risks varies across commodities Tbut few instances exist where farmers can be insured against

\footnotetext{
3Thus, the "intermediary" we are modeling is some type of marketing agent or wholesaler; in a pure insurance arrangement it might be more natural to suppose that the producer retains full residual rights to his output.

${ }^{4} U$ might be equal to the equilibrium level of utility earned in the risk-averse selfmarketing environment, but more generally might represent expected net returns in the farmer's best alternative source of employment.
} 
all risk as in the above model. ${ }^{5}$ One possible explanation for farmer exposure to risk is private information. In our model 5 this private information can be modeled by supposing that the farmer's action $a$ is unobservable to the intermediary. In this case $\Gamma$ because the distribution for $(p, q)$ depends on $a$ T the intermediary might use observations on $(p, q)$ as a way to provide incentives to the farmer for choosing the "appropriate" action.

To model the notion that $a$ is unobservable $\Gamma$ we suppose that the intermediary can only recommend that a certain $a$ be chosen. For the recommendation to be followed $\Gamma w(p, q)$ must be chosen in such a way that doing so is in the farmer's best interest. MathematicallyГthis can be expressed in the form of an incentive compatibility constraint:

$$
a \in \arg \max _{a} \int U(w(p, q)-c(a)) d G(p, q \mid a)
$$

Appending this constraint to the problem in (3) Tand supposing that the so called first-order approach is valid $\mathrm{I}^{8}$ the new condition characterizing and optimal sharing rule $w(p, q)$ is given by

$$
\frac{1}{U^{\prime}(w(p, q)-c(a))}=\theta+\mu\left(\frac{g_{a}(p, q \mid a)}{g(p, q \mid a)}+\eta(w(p, q)-c(a)) c^{\prime}(a)\right)
$$

where $\theta$ and $\mu$ are the Lagrange multipliers for the participation constraint and the incentive compatibility constraint (5) Trespectively $\eta(\cdot)$ is the farmer's Arrow-Pratt measure of relative risk aversion. Because the right-hand side of this expression includes a term that contains $(p, q)$ The intermediary's optimal sharing rule will depend on these outcomes and the farmer will face some degree of risk.

This model provides a number of predictions about how intermediation will be structured $\Gamma$ depending on the structure of the farmer's

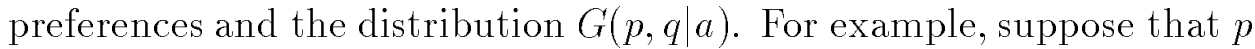
and $q$ are independently distributed Tand that the farmer's action does not influence the distribution for $p$. We can then write the likelihood ratio in $(6)$ as $g_{a}(p, q \mid a) / g(p, q \mid a)=h_{a}(q \mid a) / h(q \mid a)$ where $h(q \mid a)$ is the effort-contingent distribution of output.

This might be a reasonable description of the situation for many bulk commodities. The market price for wheat on a given day can be

\footnotetext{
${ }^{5}$ For a discussion of contract provisions and institutions for risk sharing in a sample of California commodities, see Hueth, Ligon, Wolf \& Wu (1998).

${ }^{6}$ See Jewitt (1988) for a discussion of when this approach is valid. In the next section we present simulation results that do not rely on the validity of the firstorder approach. Nevertheless, equation (5) is a convenient way of noting that compensation in the private-information optimum will generally be a function of both $p$ and $q$, while in the full-information optimum this will never be true.
} 
considered independent of the production of a single farmer $\Gamma$ and because wheat from many hundreds of producers is commingled before it is priced in downstream markets $\Gamma$ the effect of any single producer's actions on the realized price $p$ is either insignificant or impossible to discern. ${ }^{7}$ Under these conditions Tequation (6) indicates that the optimal sharing rule will be a function of $q$ alone; the grower is afforded perfect protection against price risk. That futures markets exist (allowing producers to perfectly hedge against price risk) for wheat and many other commodities that share the characteristics described above seems consistent with this prediction.

Across all types of agricultural activity $\Gamma$ farmers are almost never completely shielded from production risk. The only private $\mathrm{unsubsi-}$ dized insurance markets for agricultural risks are for specific Cobservable shocks such as hail (Knight \& Coble 1997). Again Tthis seems consistent with the predictions embodied in equation (6). That is whether or not price is independent of output $\Gamma$ it is entirely plausible that farmers be engaged in at least some production-related activities which are in some sense "hidden actions." Thus $\Gamma$ the compensation paid to farmers should always depend in some way on $q$.

Although these predictions are intuitively appealing Twe haven't said anything at all about the potential magnitude of differences across regimes. For example Trelative to each of the other regimes $\Gamma$ is expected output higher or lower when the farmer has private information? In generalГit's quite difficult to assess such magnitudes $\Gamma$ particularly in the private-information regime Cbecause it's usually not possible to obtain analytical solutions for the optimal arrangement. Nevertheless $\Gamma$ until we're able to assess these magnitudes Tthere's little that can be said about the policy implications of alternative organizational arrangements Tnor about testable implications of the model. In the subsequent section we use numerical simulation methods developed by Phelan \& Townsend (1991) and others to assess these differences. ${ }^{8}$

\section{COMPaRisons}

In this section we use numerical methods to compare compensation schedules and supply response in each of the four environments of the

\footnotetext{
${ }^{7}$ Because it is difficult to infer much about farmers' actions in markets where there is significant commingling, it is also likely that in these markets intermediaries will rely more heavily on ex-ante (before price is realized) measures of grower effort. For a related analysis that considers the role of quality measurement in tomato contracts see Hueth \& Ligon (1998).

${ }^{8}$ For an introduction to these methods see Prescott (1998) or Townsend (1993, Chapter 7)
} 
previous section. To do this ${ }^{2}$ it's necessary to specify a particular structure for preferences and technology. Here we use CES preferences of the form $U(w-c(a))=\left(w_{0}+w-c(a)\right)^{1-\gamma} /(1-\gamma)$ Tand for simplicity suppose that only output is random; price is fixed at some level $\bar{p} .^{9}$ For given effort $a \in[0.1,0.8]$ Toutput is governed by a discrete version of the gamma distribution with pdf

$$
g(q \mid a)=a^{-\kappa} q^{\kappa-1} \exp (-q / a) / \Gamma(\kappa)
$$

for $q \in[0.01,2]$. Although not necessary for the techniques we use $T$ this distribution happens to be consistent with the first-order approach for a fairly wide class of preferences Tincluding the CES specification above for $\gamma>1 / 2$ (Jewitt 1988).

Because output is random in our model Twe compare expected output given the equilibrium $a$ for each environment. However Tbefore doing so we first present a view of the technology independent of any behavioral or organizational assumptions. Figure 1 presents expected output of the producer as a function of effort for three different values of $\kappa$. The mean of the gamma distribution is given by $\kappa a$ so that expected output increases as effort increases; for any given value of $a$ Texpected output is also higher for larger $\kappa$. Note also that expected output Texcept for one minor inflection with $\kappa=3.5$ and effort very small $\Gamma$ is concave in effort. This fact is one of the reasons why the first-order approach works in this environment.

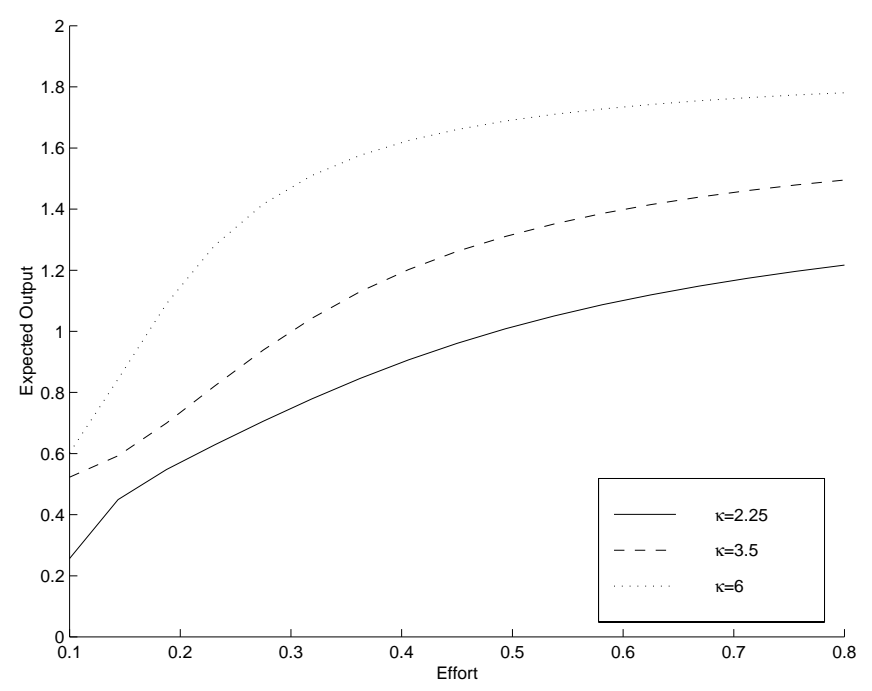

Figure 1. Stochastic Production Technology

\footnotetext{
${ }^{9}$ In the computations that follow we set $w_{0}=0.4, \gamma=0.75$, and $c(a)=a / 2$ throughout. In all but the last comparison, $\bar{p}$ is set equal to 1.
} 
Kim (1995) shows that a mean-preserving spread in the distribution of the likelihood ratio (6) improves the informational content of output as a signal of producer effort. For the gamma distribution hood ratio is given by $q / a^{2}-\kappa / a$ एso an increase in $\kappa$ produces just such a mean-preserving spread. Because the variance of the gamma distribution is given by $\kappa a^{2}$ Tan increase in $\kappa$ increases not only informational efficiency Tbut also the expected value and variability of output. An increase in $\kappa$ might therefore be thought of as the introduction of a new seed variety with a higher Tbut also more variableTexpected yield. How might such a technological change influence expected output in each regime? Figure 2 presents the answer.

The risk neutral and full-information outcomes always result in the same action $\Gamma$ so we only have three regimes to compare. Note that even though expected output increases as a function of $\kappa$ Tthis does not mean that effort also increases. For example $\mathrm{in}$ the case of the risk-averse producer marketing his own output Teffort falls as a function of $\kappa$ from 0.71 when $\kappa=2.25$ to 0.54 when $\kappa=6$. For low levels of $\kappa$ there is a fairly significant difference between the expected output of a risk-averse producer marketing his own output Tand expected output in the other two regimes. However Гit's quite remarkable how little difference there is across each of the regimes for values of $\kappa$ greater than 2 .

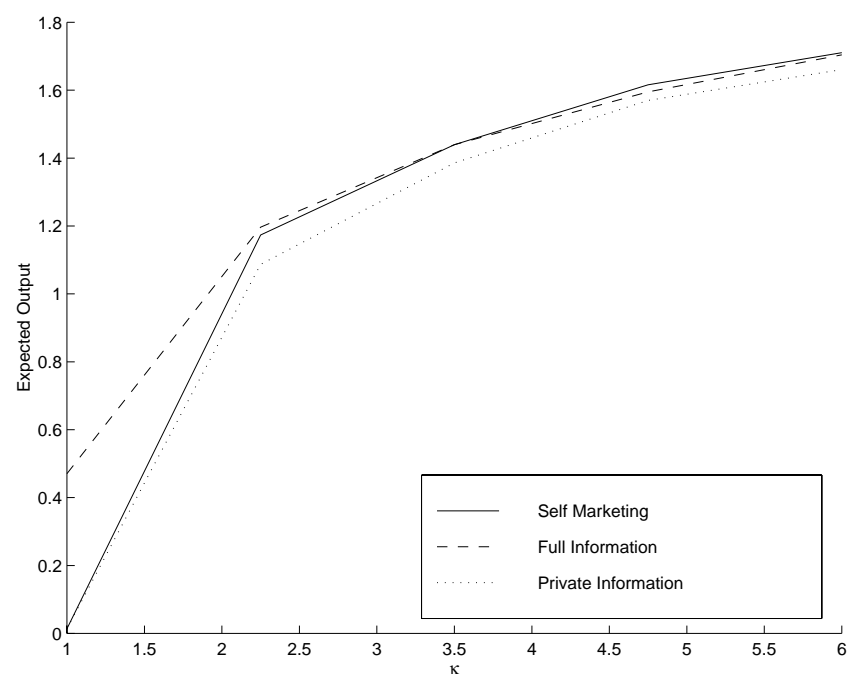

Figure 2. Supply Response to Change in Production Technology

Perhaps the most interesting aspect of the private-information model is that it delivers output-contingent payments endogenously. However $\Gamma$ 
it's generally quite difficult to assess the specific form that such payments might take. Some authors (e.g. HHart \& Holmstrom 1987) have argued that the payment schedules that emerge from models like the one in this paper are far more complicated than most real-world incentive schedules. However Tas can be seen in Figure 3 5 even when the problem being solved is quite complicated $\Gamma$ it's entirely possible that the optimal payment schedule be nearly linear. ${ }^{10}$ The near linearity we see in the compensation schedule in Figure 3 is due to the use of a distribution function $G$ in which output is a complete sufficient statistic for effort. Within this class of distributions The likelihood ratio will be a linear function of output (Lehmann 1959 Гpp. 132-133); substituting this linear form into (6) gives a linear compensation schedule when the farmer's utility of consumption is logarithmic.

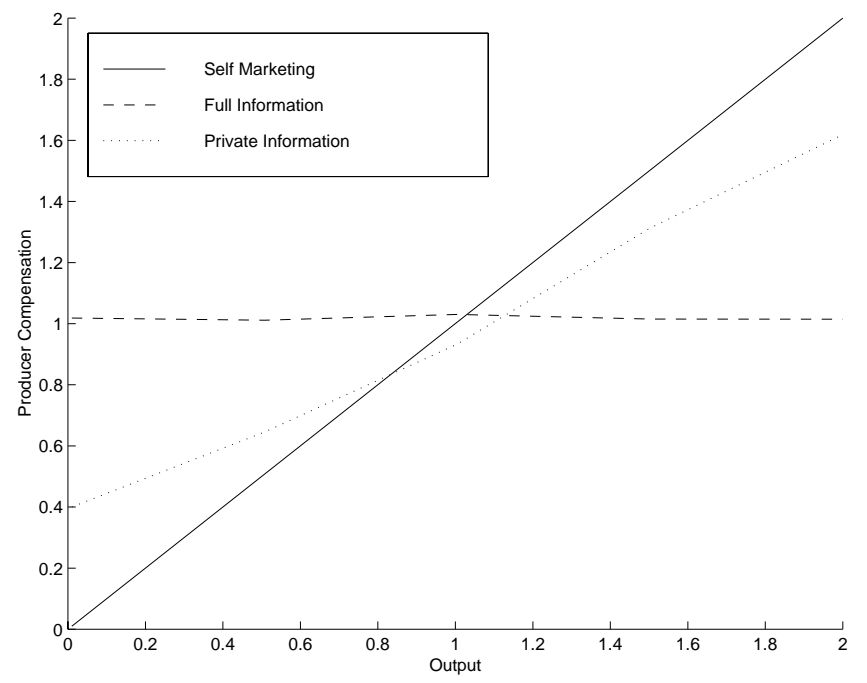

Figure 3. Producer Returns in Each Regime

The final comparative static we present is the influence of price on expected output: supply response. Again $\Gamma$ because production decisions are identical in the full-information and risk-neutral environments Wwe

\footnotetext{
${ }^{10}$ Hueth \& Ligon (1998) also find a nearly linear contract in an entirely different environment. However, we don't want to push this point too far because our field research has indicated that, at least in the case of agricultural contracts, what appears linear may actually be quite non-linear when one accounts for the many implicit and unwritten contingencies that often exist. Thus, although a linear contract might approximate the written contract well, one might find that a model with a non-linear payment schedule would do a better job of explaining actual realizations of outputs and payments for a particular intermediary and her growers.
} 
only have three comparisons to make. Figure 4 displays expected output as a function of $\bar{p} \in[0.1,1]$ for the risk-averse $\Gamma$ full-information $\Gamma$ and private-information environments. Here we find that $\Gamma$ relative to each of the other environments expected output under private information is less responsive to changes in the expected price $\bar{p}$. Of course $\Gamma$ this result (as well as those presented above) is due to the particular form of preferences and technology we use. For exampleГthat output becomes more variable as the producer exerts greater effort means that effort is a risk-increasing input. Whether or not this is true for any particular situation is clearly an empirical question that could be be assessed with the appropriate data.

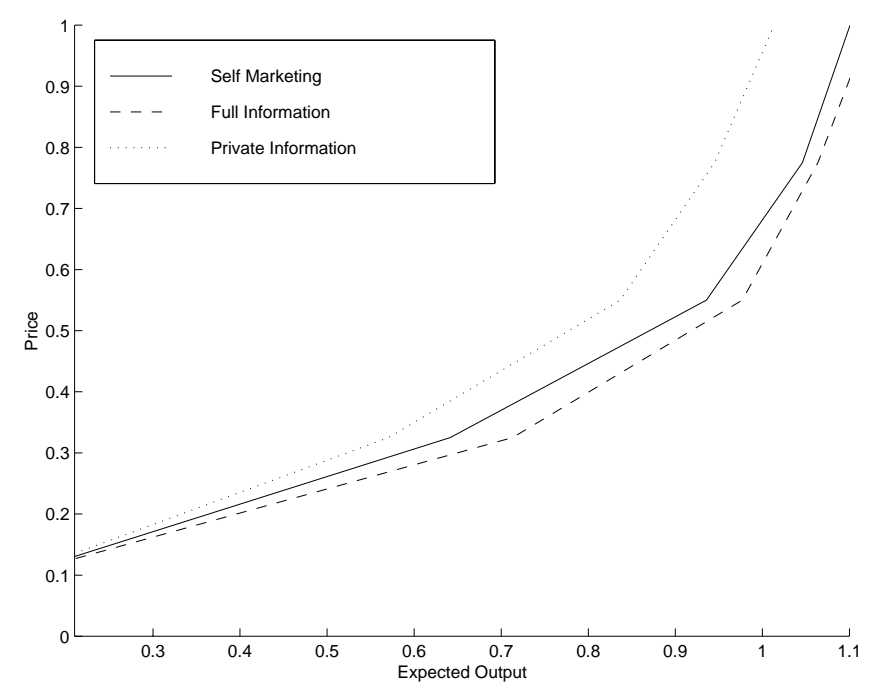

FIgURE 4. Supply Response in Each Regime

\section{Conclusion}

In this paper we consider the role of price and production risk in shaping the supply decisions of a single risk-averse farmer. Production decisions are analyzed under three different "intermediation regimes." In the first of these regimes there is no intermediation: a risk-averse farmer makes his supply decisions in an environment with both price and production risk Tand without access to any form of insurance. In the second regime $\mathrm{a}$ a risk-neutral intermediary maximizes her profit by offering the producer a contract that provides complete protection against risk. The final regime rationalizes farmer exposure to risk under risk-neutral intermediation by allowing for private information on the 
part of the farmer. Here the farmer is exposed to risk as an optimal response to an incentive problem.

Although numerous authors have considered the influence of risk on farm-level production decisions $\Gamma$ we are unaware of anyone who has done so in environment where the source of risk is endogenous-when intermediation is possible $\Gamma$ the riskiness of the farmer's compensation depends not on the distribution of prices or output $\Gamma$ but rather on the distribution of a likelihood ratio. Taking this endogeneity into account suggests that (for the particular specification of preferences and technology we consider) in an environment with private information $\Gamma$ a farmer's response to a change in expected price (ceteris paribus) will be less pronounced than in any of the other environments. 


\section{REFERENCES}

Babcock, B. \& Hennessey, D. (1996), 'Input demand under yield and revenue insurance', American Journal of Agricultural Economics 78, 416-427.

Chavas, J.-P. \& Holt, M. (1996), 'Economic behavior under uncertainty: A joint analysis of risk preferences and technology', Review of Economics and Statistics 78, 329-35.

Hart, O. \& Holmstrom, B. (1987), The theory of contracts, in T. Beweley, ed., 'Advances in Economic Theory: Fifth World Congress', Cambridge Unversity Press, Cambridge.

Holthausen, D. (1979), 'Hedging and the competitive firm under price uncertainty', American Economic Review 69, 989-95.

Hueth, B. \& Ligon, E. (1998), Quality measurement and price risk. University of California, Berkeley, Working Paper, http: //ww . are. berkeley.edu/ ${ }^{\sim}$ ligon/papers . html.

Hueth, B., Ligon, E., Wolf, S. \& Wu, S. (1998), Managing quality in fruit and vegetable contracts: Input control, monitoring, measuring, and price risk. Iowa State University, Working Paper, http: //ww . public.iastate.edu/ ־bhueth/papers.html.

Jewitt, I. (1988), 'Justifying the first-order approach to principal agent problems', Econometrica 56, 1177-1190.

Kim, S. (1995), 'Efficiency of an information system in an agency model', Econometrica 63, 89-102.

Knight, T. \& Coble, K. (1997), 'Survey of u.s. multiple peril crop insurance literature since 1980', Review of Agricultural Economics 19, 128-56.

Lehmann, E. L. (1959), Testing Statistical Hypotheses, John Wiley, New York.

Leland, H. (1972), 'Theory of the firm facing uncertain demand', American Economic Review 72, 278-91.

Lin, W. (1977), 'Measuring aggregate supply response under instability', American Journal of Agricultural Economics 59, 903-907.

Moschini, G. \& Hennessey, D. (1998), Uncertainty, risk aversion, and risk management for agricultural producers, in B. Gardner \& G. Rausser, eds, 'Handbook of Agricultural Economics', North Holland. Forthcoming.

Phelan, C. \& Townsend, R. (1991), 'Computing multi-period, informationcontrained optima', Review of Economic Studies 58, 853-882.

Pope, R. \& Kramer, R. (1979), 'Production uncertainty and factor demands for the competitive firm', Southern Economic Journal 46, 489-501.

Prescott, E. (1998), An introduction to computing moral hazard problems. Forthcoming, Federal Reserve Bank of Richmond, Economic Quarterly.

Ramaswami, B. (1993), 'Supply response to agricultural insurance: Risk reduction and moral hazard effects', American Journal of Agricultural Economics 75, 914-925.

Sandmo, A. (1971), 'On the theory of the competitive firm under price uncertainty', American Economic Review 61, 65-73.

Townsend, R. (1993), The Medieval Village Economy, Princeton University Press, Princeton.

Department of Economics, Iowa State University, bhueth@iastate.edu 
Department of Agricultural and Resource Economics, University of California, Berkeley, ligon@are.berkeley.edu 